\title{
Spatial expression pattern of serine proteases in the blood fluke Schistosoma mansoni determined by fluorescence RNA in situ hybridization
}

\author{
Lenka Ulrychová1,2, Pavel Ostašov ${ }^{3}$, Marta Chanová ${ }^{4}$, Michael Mareš ${ }^{1}$, Martin Horn ${ }^{1 *+}$ @i] and Jan Dvořák $5^{5^{*}}$
}

\begin{abstract}
Background: The blood flukes of genus Schistosoma are the causative agent of schistosomiasis, a parasitic disease that infects more than 200 million people worldwide. Proteases of schistosomes are involved in critical steps of host-parasite interactions and are promising therapeutic targets. We recently identified and characterized a group of S1 family Schistosoma mansoni serine proteases, including SmSP1 to SmSP5. Expression levels of some SmSPs in S. mansoni are low, and by standard genome sequencing technologies they are marginally detectable at the method threshold levels. Here, we report their spatial gene expression patterns in adult S. mansoni by the high-sensitivity localization assay.
\end{abstract}

Methodology: Highly sensitive fluorescence in situ RNA hybridization (FISH) was modified and used for the localization of mRNAs encoding individual SmSP proteases (including low-expressed SmSPs) in tissues of adult worms. High sensitivity was obtained due to specifically prepared tissue and probes in combination with the employment of a signal amplification approach. The assay method was validated by detecting the expression patterns of a set of relevant reference genes including SmCB1, SmPOP, SmTSP-2, and Sm29 with localization formerly determined by other techniques.

Results: FISH analysis revealed interesting expression patterns of SmSPs distributed in multiple tissues of S. mansoni adults. The expression patterns of individual SmSPs were distinct but in part overlapping and were consistent with existing transcriptome sequencing data. The exception were genes with significantly low expression, which were also localized in tissues where they had not previously been detected by RNA sequencing methods. In general, SmSPs were found in various tissues including reproductive organs, parenchymal cells, esophagus, and the tegumental surface.

Conclusions: The FISH-based assay provided spatial information about the expression of five SmSPs in adult S. mansoni females and males. This highly sensitive method allowed visualization of low-abundantly expressed genes that are below the detection limits of standard in situ hybridization or by RNA sequencing. Thus, this technical approach turned out to be suitable for sensitive localization studies and may also be applicable for other trematodes. The results

\footnotetext{
*Correspondence: horn@uochb.cas.cz; hdvorak76@outlook.com

${ }^{\dagger}$ Martin Horn and Jan Dvořák contributed equally to this work

${ }^{1}$ Institute of Organic Chemistry and Biochemistry, The Czech Academy

of Sciences, Flemingovo n. 2, 16610 Prague, Czech Republic

${ }^{5}$ Department of Zoology and Fisheries, Centre of Infectious Animal

Diseases, Faculty of Agrobiology, Food and Natural Resources, Czech

University of Life Sciences in Prague, Kamýcká 129, 16500 Prague 6, Czech

Republic

Full list of author information is available at the end of the article
}

\section{$\triangle B M C$}

Ther(s) 2021. This article is licensed under a Creative Commons Attribution 4.0 International License, which permits use, sharing, adaptation, distribution and reproduction in any medium or format, as long as you give appropriate credit to the original author(s) and the source, provide a link to the Creative Commons licence, and indicate if changes were made. The images or other third party material in this article are included in the article's Creative Commons licence, unless indicated otherwise in a credit line to the material. If material is not included in the article's Creative Commons licence and your intended use is not permitted by statutory regulation or exceeds the permitted use, you will need to obtain permission directly from the copyright holder. To view a copy of this licence, visit http://creativeco mmons.org/licenses/by/4.0/. The Creative Commons Public Domain Dedication waiver (http://creativecommons.org/publicdomain/ zero/1.0/) applies to the data made available in this article, unless otherwise stated in a credit line to the data. 
suggest that SmSPs may play roles in diverse processes of the parasite. Certain SmSPs expressed at the surface may be involved in host-parasite interactions.

Keywords: Platyhelminthes, Blood fluke, Schistosoma mansoni, mRNA detection, Transcript, Fluorescence RNA in situ hybridization, Serine proteases

\section{Background}

Human schistosomiasis is a chronic infectious disease affecting more than 200 million people in 76 countries, mostly in tropical and subtropical areas, caused by flukes of the genus Schistosoma [1]. Current treatments rely on one drug, praziquantel, and no effective vaccine has yet been developed [2]. Several schistosome species infect humans, with three of the most abundant species being Schistosoma haematobium, which causes urinary schistosomiasis, and Schistosoma japonicum and Schistosoma mansoni, causing intestinal schistosomiasis [3]. Humans are infected by schistosome larvae called cercariae, which are released into freshwater by intermediate snail hosts. Cercariae penetrate human skin and subsequently develop into adult male or female worms in the host vascular system, where they produce hundreds of eggs per day [4]. Morbidity arises from immunopathological reactions to and entrapment of schistosome eggs in various tissues [5].

The genome of $S$. mansoni was sequenced, and numerous genes were identified or predicted [6]. In the postgenomic era, however, it is vital to elucidate functions of these genes. Quantification and spatial distribution of RNA transcripts in individual cells of the whole multicellular organism helps to narrow potential functions of individual genes [7-9]. RNA in situ hybridization represents a powerful tool to investigate the spatial distribution of gene transcripts $[7,10]$. Hybridization methods are based on the binding of an individual RNA target with specifically designed complementary RNA probes labeled with a reporter molecule, such as digoxigenin (DIG). Such probes can then be detected by specific antibodies recognizing this molecule. These antibodies are conjugated with enzymes allowing visualization of the probe via fluorescent or colored staining. However, detection and visualization of low-abundantly expressed transcripts is challenging in multicellular organisms such as schistosomes with diverse cellular and tissue organization.

Blood flukes of the genus Schistosoma are unique among the trematodes because they have evolved separate sexes [11]. They are acoelomates, animals without a body cavity except for the gut and reproductive organs (testes, vitellaria, ovary, and oviduct). The interior body is filled with mesodermal tissue called parenchyma, which is composed of diverse cell subtypes such as stem cells
[12], cells derived for example from neuro-excretory systems [13, 14], tegumental cell bodies [14, 15], and other yet undefined cell types with unknown functions. The entire surface of adult schistosomes is covered by the syncytial layer called the tegument [16].

Serine proteases (SPs) are key virulence factors for many parasitic helminths; they are critical for parasite invasion, migration, nutrition, and reproduction, and they facilitate adaption to and evasion from the host's physiological and immune responses [17-19]. Recently, we found that the S1 family of serine proteases of $S$. mansoni (SmSPs) significantly contributed to proteolytic activities detected in excretory/secretory $(\mathrm{E} / \mathrm{S})$ products of blood-dwelling developmental stages [20]. We uncovered a repertoire of SmSPs (designated SmSP1 to SmSP5) by performing a series of genomic, transcriptomic, proteolytic, and phylogenetic analyses [21], and described the major SmSP, SmSP2, at the protein level [22].

In this work, we used the fluorescence in situ hybridization (FISH) technique based on a detection of DIGlabeled RNA probes by anti-DIG antibody conjugated with horseradish peroxidase (HRP) [23] to investigate RNA distribution in adult male and female $S$. mansoni. The technique was validated by detecting a set of target RNA transcripts with known localization, the digestive protease cathepsin B1 of S. mansoni (SmCB1) [24-27], the surface-associated prolyl oligopeptidase (SmPOP) [28], the tegumental tetraspanin SmTsp-2 [29-31], and Sm29, a membrane-bound glycoprotein found at the $S$. mansoni tegument [31-34]. A probe targeting a bacterial neomycin gene (neo), which is absent in the $S$. mansoni genome, was used as a negative control. The validated FISH technique was then used to determine the tissue distribution of transcripts of individual SmSP genes (SmSP1 to SmSP5) $[18,21]$. The analysis revealed complex expression patterns of all SmSPs generally consistent with existing transcriptome sequencing data [35, 36]. Moreover, the method also enabled us to localize the genes with significantly low expression in tissues where they had not previously been detected by RNA sequencing (RNAseq) methods.

\section{Methods}

\section{Schistosome material}

S. mansoni (a Puerto Rican LSHTM strain) was maintained in the laboratory by cycling between the 
intermediate snail hosts, Biomphalaria glabrata, and outbred ICR (CD-1) mice as definitive hosts. Infective larvae (cercariae) were shed by light stimulation from infected snails placed in bottled drinking water. Adult female mice were infected by immersing their feet and tail into $50 \mathrm{~mL}$ of water containing approximately 300 cercariae for $45 \mathrm{~min}$. Six weeks post-infection, mice were over-anesthetized by an intraperitoneal injection of ketamine (Narkamon $5 \%-1.2 \mathrm{~mL} / \mathrm{kg}$ body weight) and xylazine (Rometar $2 \%-0.6 \mathrm{~mL} / \mathrm{kg}$ body weight), and the worms were recovered from the hepatic portal system by transcardial perfusion with RPMI 1640 medium (SigmaAldrich) as described previously [20, 22, 37].

\section{Isolation of mRNA and CDNA synthesis}

Collected adult worms were washed three times with 50 $\mathrm{mL}$ phosphate-buffered saline (PBS) and re-suspended in $500 \mu \mathrm{L}$ of the Trizol reagent (Thermo Fisher), and RNA was isolated as described previously [38]. Single-stranded cDNA was synthesized from total RNA by SuperScript III reverse transcriptase (Thermo Fisher) and an oligo $(\mathrm{dT})_{23}$ primer according to the manufacturer's protocol. The final cDNA product was purified using the QIAquick PCR purification kit (Qiagen) and stored at $-20^{\circ} \mathrm{C}$.

\section{Probe production}

Probes (600-1500 nucleotides) were designed to hybridize with the catalytic domain sequences of selected target gene transcripts. DNA templates for probe synthesis were amplified by polymerase chain reaction (PCR) from S. mansoni cDNA using gene-specific primers (Additional file 1: Table S1). The PCR products were cloned into the pGEM-T Easy vector (Promega), and the cloned sequences were verified by DNA sequencing. Constructs were linearized by restriction enzymes (NEB) selected based on insert orientation within the construct. Linearized plasmid DNA $(1 \mu \mathrm{g})$ was used as a template to generate digoxigenin (DIG)-labeled probes by in vitro transcription using the DIG RNA labeling kit (SP6/T7) (Roche). The probes were transcribe using either SP6 or T7 RNA polymerases (final concentration $1 \mathrm{U}$ per $1 \mu \mathrm{L}$ ) at $37^{\circ} \mathrm{C}$ for $2 \mathrm{~h}$ according to the manufacturer's protocol. DNA templates were removed by incubation with DNase I (final concentration $1 \mathrm{U}$ per $1 \mu \mathrm{L}$ ) at $37^{\circ} \mathrm{C}$ for $15 \mathrm{~min}$. The reactions were terminated by the addition of EDTA (final concentration $0.02 \mathrm{M}$ ), and the probes were stored at $-20{ }^{\circ} \mathrm{C}$ prior to use. DIG-labeled "antisense" Neo RNA, which is a component of the SP6/T7 DNA labeling kit (Roche), was used as a control probe. The DNA construct containing the Sm29 sequence was kindly provided by Christoph G. Grevelding (Justus Liebig University, Giessen, Germany). All hybridization probes were verified by the sequencing. The probe specificity was verified by BlastN analysis on the National Center for Biotechnology Information (NCBI) database. Sequences shared $100 \%$ identity with the studied genes and showed no significant similarities to other genes in the organism [35], including those used in our study.

\section{Tissue preparation for fluorescence in situ hybridization}

Following perfusion, S. mansoni couples were separated on ice by gentle prodding with a brush, washed three times in $50 \mathrm{~mL}$ of PBS, and fixed with boiling $4 \%$ formaldehyde solution (Sigma-Aldrich). Worms were left to cool to $25{ }^{\circ} \mathrm{C}$, incubated at $25{ }^{\circ} \mathrm{C}$ for $90 \mathrm{~min}$, and dehydrated by incubation in a series of increasing ethanol concentrations $(25 \%, 50 \%, 70 \%, 90 \%, 96 \%, 100 \% \mathrm{v} / \mathrm{v}$ at $25{ }^{\circ} \mathrm{C}$ for $5 \mathrm{~min}$ each). Incubation with $100 \%$ ethanol was performed twice for $5 \mathrm{~min}$. Subsequently, males were incubated in methyl benzoate (Sigma-Aldrich) at 25 ${ }^{\circ} \mathrm{C}$ for $45 \mathrm{~min}$, females for $20 \mathrm{~min}$. Worms were washed twice at $25{ }^{\circ} \mathrm{C}$ for 5 min each in benzene (Sigma-Aldrich), which was then exchanged three times with $60{ }^{\circ} \mathrm{C}$ hot paraffin (Paraplast X-TRA, Leica). All incubation and washing steps were performed in approximately $50 \mathrm{~mL}$ of appropriate solution. After the last wash, worms were incubated in $20 \mathrm{~mL}$ paraffin (Leica) at $60{ }^{\circ} \mathrm{C}$ for $2 \mathrm{~h}$ and then embedded in paraffin blocks. Sections $(6 \mu \mathrm{m})$ were prepared on a microtome (Shandon Finesse ${ }^{\circledR} \mathrm{ME}+$ ) and applied to X-TRA adhesive glass slides (Leica).

\section{Pre-hybridization tissue treatment}

Slides with fixed tissue sections $(6 \mu \mathrm{m})$ were de-paraffinized by two 5 -min washes in xylene followed by two 5 -min washes in $100 \%$ ethanol. Sections were rehydrated by incubation in a series of decreasing ethanol concentrations $(100 \%, 96 \%, 90 \%, 70 \%, 50 \%, 25 \% \mathrm{v} / \mathrm{v})$ at $25{ }^{\circ} \mathrm{C}$ for 5 min each, followed by a wash in diethyl-pyrocarbonate (DEPC, Sigma-Aldrich)-treated water for $5 \mathrm{~min}$. To minimize background quench by endogenous peroxidases and improve cell permeability, slides were incubated in $0.2 \mathrm{~N} \mathrm{HCl}$ at $25^{\circ} \mathrm{C}$ for $20 \mathrm{~min}$, followed by incubation in $0.01 \mathrm{M}$ sodium citrate, $\mathrm{pH} 6.0$, in a boiling water bath for $15 \mathrm{~min}$. Slides were then cooled to $25^{\circ} \mathrm{C}$ for $30 \mathrm{~min}$, incubated in $0.2 \%$ glycine for $5 \mathrm{~min}$, followed by incubation in ice-cold $20 \%$ acetic acid for $15 \mathrm{~s}$ and PBS at $25^{\circ} \mathrm{C}$ for 5 min. Finally, the slides were incubated in $20 \%$ glycerol at $25^{\circ} \mathrm{C}$ for 15 min and briefly rinsed with $2 \times$ saline sodium citrate buffer (SSC, Sigma-Aldrich). All incubation and washing steps were performed in $150 \mathrm{~mL}$ of appropriate solution.

\section{RNA in situ hybridization}

To denature secondary RNA structures within the tissues, sections were preheated to $70{ }^{\circ} \mathrm{C}$ for $10 \mathrm{~min}$ prior to hybridization and briefly cooled on an ice-cold metal 
plate. One hundred microlitres of hybridization mixture A [ $5 \times$ SSC, $1 \times$ PBS, $0.1 \%$ torula yeast RNA (SigmaAldrich)] containing RNA probe $(0.5-5 \mathrm{ng} / \mathrm{mL})$ was heated to $70{ }^{\circ} \mathrm{C}$ to denature secondary RNA structures. The mixture was then briefly cooled on ice, immediately mixed with $160 \mu \mathrm{L}$ of hybridization solution B [50\% formamide, $10 \%$ dextran sulfate molecular weight 4000 (Sigma-Aldrich) and 1\% Tween 20], applied to sections, and covered with a coverslip. All samples were then hybridized in a moisture chamber at $42^{\circ} \mathrm{C}$ for $16 \mathrm{~h}$.

\section{Post-hybridization treatment}

After hybridization, the slides were washed in $2 \mathrm{x}$ SSC with $0.1 \%$ Tween 20 at $42{ }^{\circ} \mathrm{C}$ for $15 \mathrm{~min}$, followed by washes in $1 \mathrm{x}$ SSC, $0.5 \mathrm{x}$ SSC, and $0.1 \mathrm{x}$ SSC, each at 25 ${ }^{\circ} \mathrm{C}$ for $15 \mathrm{~min}$. The slides were then washed twice for 5 min with MAB buffer (0.1 M maleic acid, pH 7.5, $0.15 \mathrm{M}$ $\mathrm{NaCl})$ at $25^{\circ} \mathrm{C}$ and incubated in $4 \%$ blocking solution [4\% heat-inactivated horse serum (Sigma-Aldrich) in MAB buffer] for $30 \mathrm{~min}$. The DIG-labeled probes hybridized with tissue RNA were labeled by incubation with antidigoxigenin antibody conjugated with horseradish peroxidase (anti-DIG-HRP antibody, Perkin Elmer) diluted 1:500 in $2 \%$ blocking solution ( $2 \%$ heat-inactivated horse serum in MAB buffer) at $37{ }^{\circ} \mathrm{C}$ for $2 \mathrm{~h}$. Excess antibody was then removed by three washes in MAB at $25{ }^{\circ} \mathrm{C}$ for $10 \mathrm{~min}$. All incubation and washing steps were performed in $150 \mathrm{~mL}$ of appropriate solution. Hybridized probes labeled with DIG-HRP antibodies were visualized by the Tyramide Signal Amplification (TSA) system with the Cyanine Plus 5 Tyramide Reagent fluorescence system (Perkin Elmer) according to the manufacturer's protocol. Briefly, the slides were washed three times with $150 \mathrm{~mL}$ TNT buffer $(0.1 \mathrm{M}$ Tris-HCl, pH 7.5, 0.15 $\mathrm{M} \mathrm{NaCl}, 0.05 \%$ Tween 20) for $5 \mathrm{~min}$ each, and incubated in a moisture chamber with Cyanine Plus 5 dye diluted 1:50 in $500 \mu \mathrm{L}$ of $1 \times$ Plus Amplification Diluent for 10 min. After three washes with $150 \mathrm{~mL}$ TNT buffer for 5 min, sections were rinsed in DEPC-water and mounted in ProLong Diamond Antifade reagent containing DAPI (Thermo Fischer).

\section{Microscope observation}

Fluorescent signals were detected using an Olympus IX83 fluorescence microscope (Olympus) equipped with a pco. edge 5.5 camera. To define the background signal threshold, samples underwent FISH procedure without probe, or hybridization with the control probe carrying the sequence of a bacterial neomycin-resistance gene (neo) which is not present in the schistosome genome. Microscopy images were processed using Fiji software [39]. Images were collected from three parts of adult worms: the anterior head region (females: from ventral sucker to the anterior margin of ovaries; males: extending from the anterior extremity of the schistosome to the ventral sucker), the middle region (females: containing mature and immature oocytes and oviduct; males: containing testis), and the posterior hind region (females: containing vitellaria and gut; males: the body part located posterior to the margin of testes and focusing on the parenchyma, tegument, and gut). This division is very coarse and used for simplification; some organs may occur in several regions. Moreover, obtaining a representative image of the anterior region of the female (head with esophagus) is generally problematic because fixation always causes some degree of contraction and distortion, and sectioning is difficult. To verify reproducibility, all experiments including probe production, tissue preparation, and FISH procedure were carried out in at least two independent experiments.

\section{Results \\ Validation of fluorescence RNA in situ hybridization (FISH) for the tissues of S. mansoni adults}

We used FISH based on digoxigenin (DIG)-labeled RNA probes [23] to localize individual RNA molecules in $S$. mansoni adult males and females. Initially, the FISH assay was validated by localization of a set of relevant control genes with a known localization [determined using other localization techniques, e.g. immunolocalization or whole-mount in situ hybridization (WISH)]. The genes used for validation were digestive protease SmCB1 [40], surface-localized protease SmPOP [28], and tegumental proteins SmTsp-2 [41] and Sm29 [33].

The localization results obtained for individual target RNAs are summarized in Fig. 1. Generally, transcripts of the genes were localized by FISH in the same tissues of adult males or females as previously described. Due to the high sensitivity of the technique, additional new localizations of some transcripts were found. The transcript profiles for SmCB1, SmPOP, SmTsp-2, and Sm29 also corresponded to previous RNAseq data obtained for S. mansoni adults and their gonads (http://schisto.xyz/; $[35,36])$.

Digestive SmCB1 was previously detected in the gastrodermis [40], and its activity was also demonstrated by fluorescence histochemistry in the vitellaria [42]. We confirmed localization of the transcripts coding SmCB1 in the gastrodermis of females and males and in the vitellaria (Figs. 2 and 3). Additionally, in females, a significant signal was present in the oviduct and a faint signal was detected in the parenchyma surrounding mature oocytes (Fig. 2). In males, faint fluorescence was present in testicular cells and in the region of the esophagus (Fig. 3).

SmPOP is a protease that was immunolocalized to the tegument (including tubercles) and the parenchyma of 


\begin{tabular}{|c|c|c|c|c|c|c|c|c|c|c|c|c|c|c|c|c|c|c|}
\hline & 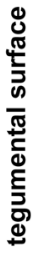 & 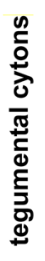 & 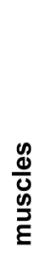 & 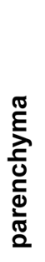 & 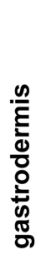 & 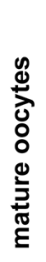 & 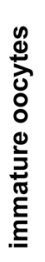 & $\begin{array}{l}\frac{\mathrm{J}}{\mathrm{J}} \\
\frac{0}{2}\end{array}$ & 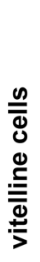 & & 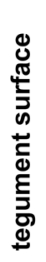 & 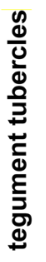 & 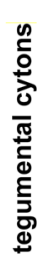 & 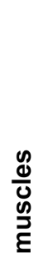 & 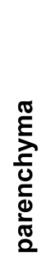 & 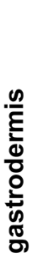 & 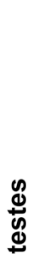 & 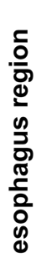 \\
\hline SmSP1 & - & - & - & + & - & + & - & + & + & SmSP1 & - & - & + & - & + & - & + & + \\
\hline SmSP2 & + & + & - & + & - & + & + & - & + & SmSP2 & - & - & + & - & + & - & + & + \\
\hline SmSP3 & - & - & - & + & - & + & - & - & + & SmSP3 & - & - & - & - & + & - & + & + \\
\hline SmSP4 & + & + & - & + & - & + & + & + & + & SmSP4 & - & + & + & - & + & - & + & + \\
\hline SmSP5 & - & - & - & + & - & + & + & - & + & SmSP5 & - & - & - & - & + & - & + & - \\
\hline SmCB1 & - & - & - & - & + & - & - & + & + & SmCB1 & - & - & - & - & - & + & + & + \\
\hline SmPOP & - & + & - & + & - & + & + & + & + & SmPOP & - & + & + & - & + & - & + & + \\
\hline SmTsp-2 & - & + & - & + & - & + & + & + & + & SmTsp-2 & - & + & + & - & + & - & + & + \\
\hline Sm29 & - & + & - & + & - & - & - & - & - & Sm29 & - & - & + & - & + & - & + & + \\
\hline $\mathrm{Neo}$ & - & - & - & - & - & - & - & - & - & $\mathrm{Neo}$ & - & - & - & - & - & - & - & - \\
\hline No probe & - & - & - & - & - & - & - & - & - & No probe & - & - & - & - & - & - & - & - \\
\hline
\end{tabular}

Fig. 1 An overview of localization of gene sense transcripts in S. mansoni adult male and female tissues using FISH. Transcripts whose localizations were observed in the given tissue are highlighted in pink (females) or blue (males). Light shades represent a faint positive signal for a given transcript. Localization in the esophagus region was possible only in the sections of adult males; obtaining a representative section of the smaller females' head region (containing esophagus) is generally problematic

adult parasites [28]. In males, transcripts of SmPOP were detected in the tegumental cytons and, surprisingly, in tegumental tubercles-morphological structures above the muscle layer (Additional file 2: Figure S1a)-which are not expected to contain RNA molecules and where RNA translation should therefore not occur. Transcripts of SmPOP were also detected in parenchyma, around the esophagus, and in the testes (Fig. 3). In females, SmPOP was distributed in the parenchyma throughout the whole body, a strong signal was detected in the oviduct and the vitellaria, and a faint signal was also detected in oocytes (Fig. 2).

SmTsp-2 and Sm29 are known as tegumental markers [29, 30, 33, 41, 43, 44]. Transcripts of SmTsp-2 were detected in the tegument of both males and females and in the parenchyma (Figs. 2 and 3). In females, transcripts were also detected in the ovary, vitellaria, and oviduct, and in males, around the esophagus and in the testes. Surprisingly, but in accordance with previous findings [14], SmTsp-2 transcripts were also localized in the tegumental tubercles (Additional file 2: Figure S1).

Contrary to SmTsp-2, transcripts of Sm29 had a distinct expression pattern. In females (Fig. 2), strong fluorescence was found only in the parenchyma and tegumental cytons in the anterior regions. In males, Sm29 mRNA was found in the testes, some parenchymal cell subtypes, in the esophageal area, and in the tegumental cytons but not in the tegumental surface layer and tubercles (Fig. 3, Additional file 2: Figure S1a). No signal was detected in the ovary, oviduct, or gut of either gender (Figs. 2 and 3).

Also, sense probes hybridizing to antisense gene transcripts that do not encode proteins were designed for genes of all transcripts studied (Additional file 3: Figures S2 and S3) and used in the FISH procedure. Only antisense transcripts of SmPOP and SmCB1 were found solely in the female oviduct. No antisense transcripts of these genes were detected in the tissues of the males.

Non-specific bindings and backgrounds were analyzed using two different approaches: (i) hybridization with a probe targeting a sequence-coding bacterial gene (neo) which is not naturally present in genomes of schistosomes, and (ii) hybridization procedure without any probe. No signals were detected after the hybridization procedure in either case (Additional file 3: Figure S4).

The validated and optimized FISH therefore represents a robust method for detection of RNA in sections of adult $S$. mansoni. This was documented by the precise localization of selected transcripts, and the result corresponded to previous transcript profiling as determined by other methods such as immunolocalization $[28,33,40,43]$ or differential RNAseq [35, 36]. 


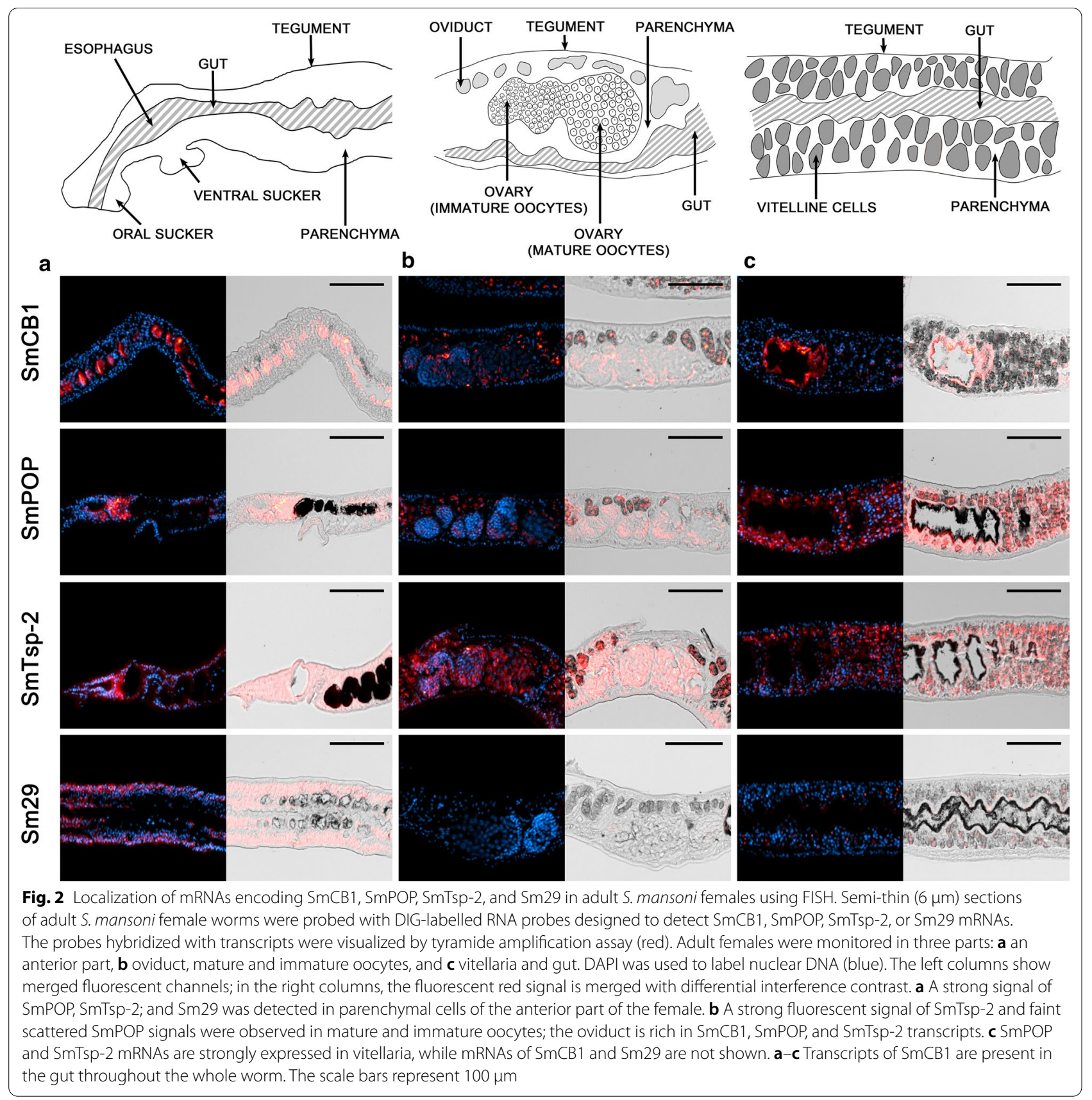

\section{FISH revealed a diverse distribution of serine proteases SmSP1 to SmSP5 in adult S. mansoni}

The FISH technique was used to precisely localize transcripts encoding serine proteases SmSP1 to SmSP5 in adult $S$. mansoni. Results showing localization of SmSPs RNA are summarized in Fig. 1. Generally, transcripts of all SmSP1 to SmSP5 were detected in the parenchyma with different patterns. No expression of SmSPs was detected in the gastrodermis or the muscles. In other tissues, SmSPs showed diverse expression patterns that are described below (Figs. 4 and 5).

In females, SmSP1 transcripts were detected in the oviduct, vitellaria, and mature but not immature oocytes (Fig. 4). In males, SmSP1 genes were transcribed in the tegumental cytons, the area around the esophagus, and in the testes (Fig. 5). Low expression occurred in the parenchyma in both genders (Figs. 4 and 5). 


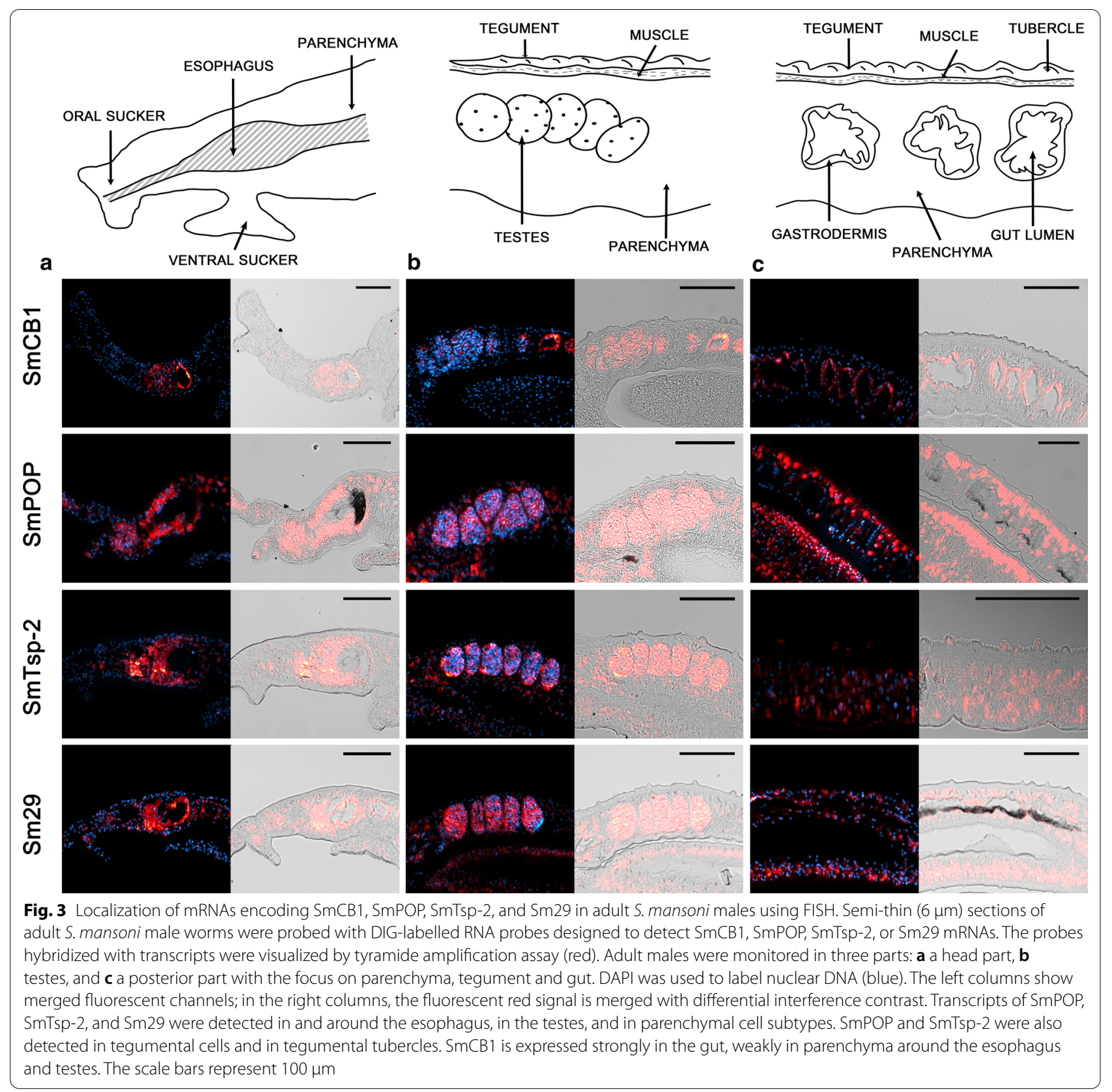

SmSP2 transcripts were found in the esophagus and parenchyma throughout the bodies of both genders and also in the tegumental cytons, which agrees with previously described SmSP2 immunolocalization [22] (Figs. 4 and 5, Additional file 2: Figure S1a). In females, SmSP2 gene transcripts were also found in mature and immature oocytes, vitellaria, and in the tegumental surface above the muscle layer (Fig. 4); in males in testes (Fig. 5). No expression occurred in the tubercles or in the oviduct.

SmSP3 mRNA was found only in the parenchymal tissue surrounding the vitellaria in the posterior region of females, in the vitelline cells, and weakly in the mature oocytes (Fig. 4). Males expressed SmSP3 only in the esophagus region, parenchyma, and testes (Fig. 5). No fluorescence was detected in the immature oocytes, the oviduct, the tegumental surface, or the tegumental tubercles (Figs. 4 and 5).

SmSP4 was abundantly expressed in parenchymal cells and tegumental cytons in whole adult worms. SmSP4 transcripts were also detected in females in the tegumental surface, oviduct, mature and immature oocytes, and the vitelline cells (Fig. 4). Expression of SmSP4 in males 


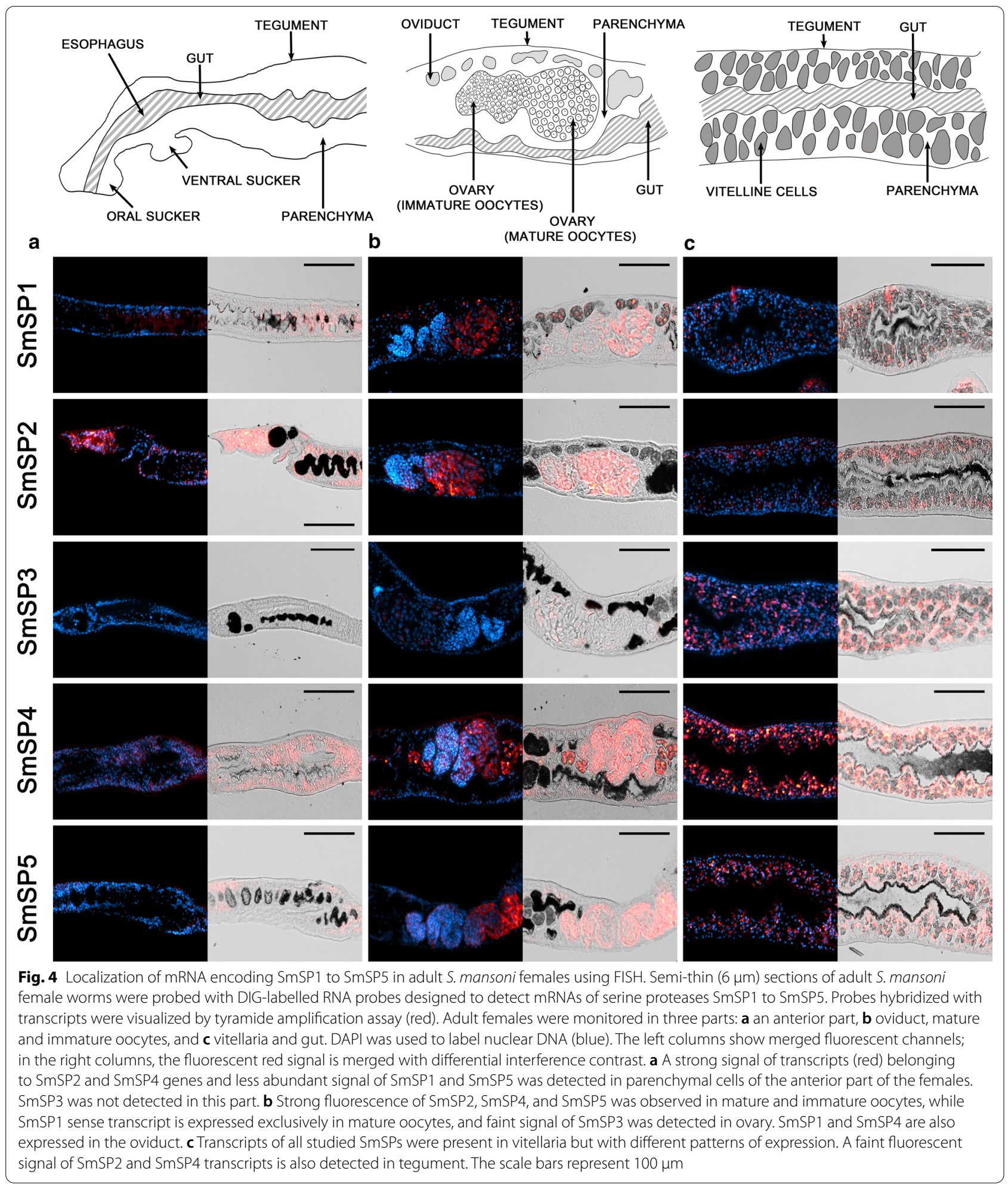




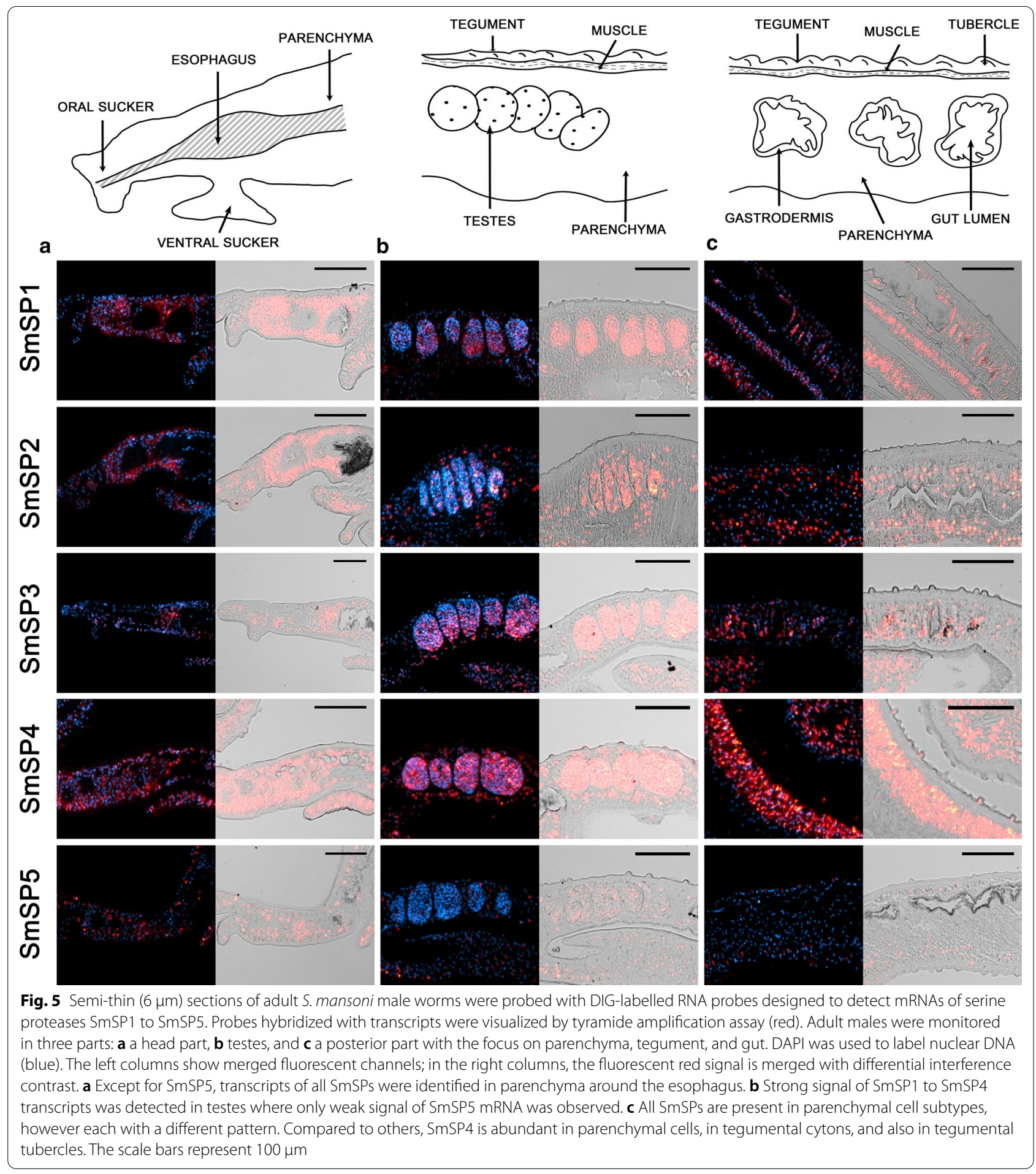

occurred additionally in the testes and the tegumental tubercles (Fig. 5).

SmSP5 expression was revealed in mature and immature oocytes, and in the vitelline cells. Weak fluoresce was detected in the parenchyma, none in the oviduct (Fig. 4). In males, SmSP5 showed a different expression pattern compared to other SmSPs: a small number of parenchymal cells expressed SmSP5. In comparison with other SmSPs, only faint fluorescence was detected 
in the esophageal region and the testes, and no SmSP5 signal was detected in the tegument (Fig. 5).

As in the case of transcripts of proteins with known localizations (see above), sense probes for the detection of antisense transcripts of all SmSPs were designed and used to hybridize with the female and male dissected tissues. Only antisense transcripts of SmSP5 were found in the oviducts of females where no sense SmSP5 was expressed (Additional file 3: Figures S5 and S6).

FISH technology therefore allowed detection of the diverse localization of transcripts of all SmSP genes in adult schistosomes. The results showed their distinct distribution patterns within the tissues of males and females. A common feature for all SmSPs was the expression in parenchymal tissue; however, further expression patterns varied. None of these transcripts was detected in the gastrodermis or muscle layer.

\section{Discussion}

Family S1 serine proteases (SPs) are crucial for successful parasitism by facilitating invasion, nutrient intake, and evasion of the host immune system, and modulation of the host physiology [17, 19]. However, information about SPs in S. mansoni (SmSPs) remains limited despite current discoveries $[18,22]$. Our previous study demonstrated that SmSPs, designated SmSP1 to SmSP5, were differentially expressed among $S$. mansoni developmental stages [21]. Here, we used fluorescence in situ hybridization (FISH) to localize individual RNA molecules in $S$. mansoni adults in tissues including the esophagus, testis, ovary, vitellarium, and parenchymal and tegumental cells, including tubercles.

The FISH method was validated by detecting expression patterns for a set of transcripts of formerly described genes. We employed the previously established FISH protocol [45] by using (i) gentle tissue fixation and optimization of several pre- and post-hybridization steps with antigen retrieval, (ii) background minimization procedures, and (iii) amplification of the fluorescent signal by TSA [23]. The obtained results corresponded well with previous findings reported using other techniques: transcripts of digestive protease SmCB1 were localized in the gut, the expression of surface-localized SmPOP was detected in the parenchyma and tegument, and the mRNAs of tegumental SmTsp-2 and Sm29 were found in tegumental cytons or tegument [28, 33, 40,41]. SmPOP and Sm29 transcripts were also localized in the vitellarium, which agrees with previous studies [28, 30,33]. Lastly, the transcription profiles for SmCB1, SmPOP, SmTsp-2, and Sm29 were congruent with sequencing data obtained for S. mansoni [35, 36].

In addition to previous data, we discovered new localizations of some transcripts due to the high sensitivity of the FISH method. SmCB1 transcripts were detected in the vitellarium, whereas SmCB1 activity was previously detected by fluorescence histology only in oviducts and testes [42]. Localization of SmCB1 in vitellaria is in the line with expression of orthologous proteases from other parasitic flukes, Fasciola gigantica and Eudiplozoon nipponicum, in which cathepsin B expression was also detected in testes and vitelline cells $[46,47]$. The function of these proteases in reproductive organs is as yet unknown; however, the authors hypothesized that cathepsin B may process eggshell or yolk protein vitellogenin precursors, as described in other organisms [48-50]. In addition to localization in the tegument, SmTsp-2 and Sm29 transcripts were found in parenchyma and testes, and SmTsp-2 also in the oviduct (Figs. 2 and 3). Tetraspanins stabilize extracellular vesicles [51], and these types of vesicles are known to be secreted as well by the specific types of cells into the lumen of the oviduct [52], which may explain the abundance of tetraspanin SmTsp-2 transcripts in such a highly dynamic organ structure.

Our previous research [21] and transcriptome sequencing data $[9,35,36,53]$ revealed that SmSP2 and SmSP4 are highly abundantly transcribed in adult schistosomes and, contrarily, expression levels of SmSP1, SmSP3, and SmSP5 are low. Highly sensitive FISH analysis employed in this paper revealed expression patterns of all SmSPs (including low-abundantly expressed ones) distributed in multiple tissues of adult schistosomes, except for more specific localization identified for SmSP3 in females and SmSP5 in males. All SmSPs were commonly detected only in parenchyma of both genders (Figs. 4 and 5), but individual SmSPs showed distinct expression patterns in different subtypes of parenchymal cells (Figs. 4 and 5), indicating their unique functional roles. Distribution of SmSP1 and SmSP2 transcripts in parenchymal cells and tegument agrees with protein immunolocalization data [22, 54]. Except for SmSP5, all studied genes localized within the anterior part of males in the head area containing the esophagus. Previously, this area was shown to be highly dynamic in gene transcription; more than 1000 genes were detected. Among them, SmSP2 was found to be upregulated twofold or more in this region in comparison with the whole worm body [55]. This agrees with our results, because strong signals of SmSP2 transcripts were detected in the parenchyma of the anterior body of both genders (Figs. 4 and 5). Detection of SmSP2 transcripts in the esophageal region also fits with our previous immunolocalization data [22].

Additional new localizations of several SPs were found in some reproductive organs of male or female worms. These organs are highly dynamic, comprising 7000 transcripts of genes upregulated twofold or more in reproductive organs compared to whole worm controls [36, 
55]. Expression levels of particular genes are upregulated twofold or more after mating, and RNA storage is also frequently observed in gonadal cells $[36,56]$. Additionally, mRNA stored in spermatozoa can be transported from males to females during sexual reproduction via sperm fluid into the oocyte $[36,57]$. FISH revealed the presence of all SmSPs in gonads of both genders (Figs. 4 and 5). Contrarily, RNAseq showed (with exception of SmSP2) low or no SmSP transcripts in schistosome gonads [36]. Such divergence is probably based on distinct methodologies. RNAseq has a limited number of reads, reflecting a limited number of molecules that can be detected. Thus, low-abundant transcripts may be below the detection limit. On the other hand, FISH employed in this study has the capacity to detect every single RNA in the tissue due to amplification of the fluorescent signal by TSA (signal amplification up to 200fold), which has the ability to detect low-abundant transcripts which under normal circumstances would be part of the threshold. SmSPs may have a similar function reported for serine proteases in the gonads of several nematodes or flies: Caenorhabditis elegans or Ascaris suum employ serine proteases for spermatogenesis and sperm activation in the uterus [58, 59]; serine proteases of Drosophila melanogaster are thought to process peptides and activate enzymes inside the female reproductive ducts and mediate critical postmating responses [60].

The entire surface of adult schistosomes is covered by the syncytial layer called the tegument [16]. In contrast to females, males have additional tegumental structures called tubercles [61]. The nucleated regions of tegumental cells are also known as cell bodies or tegumental cytons, where protein-synthesizing and sorting machinery (including endoplasmic reticulum and Golgi apparatus), is situated below the musculature and has connections to the syncytial surface part via cytoplasmic connections (Additional file 2: Figure S1a). Synthesized proteins, RNAs, and other cargos are transported to the cell surface by microtubule-lined cytoplasmic channels through cytoplasmic connections. The most common destination for mRNAs within the cell is in the immediate proximity of the site of translation, i.e. close to the endoplasmic reticulum. Therefore, mRNA would be expected in the tegumental cytons but not in the surface layer [62]. Nevertheless, mRNAs of SmPOP, SmTsp2 , and SmSP4 were localized not only in tegumental cytons, but a strong signal was also detected in tegumental tubercles (Figs. 3 and 5). These results suggest that a not fully understood transport mechanism exists for moving mRNA molecules from cytons to the schistosome surface. This cargo is usually transported through the tegument via extracellular vesicles sent to the outer environment. Recently, SmSP2, SmTsp-2, and Sm29 were identified in extracellular vesicles released from Schistosoma [63], which coincides with our localization in the tegumental tubercles.

The localization of mRNAs within eukaryotic cells is enormously diverse [64, 65]. The endoplasmic reticulum and Golgi apparatus provide well-established membranesorting machinery to shuttle mRNAs to distant regions within the cell [64]. These mRNAs are usually stored in granules and are ready for immediate or emergency use in a wide range of processes $[64,66]$. They can (i) be reactivated, translated into proteins, and used in various rapid emergency processes including stress responses, metabolic reprogramming, repair of stress-induced damage, and adaptation to changed conditions; (ii) play a role in the repression of other mRNA species; or (iii) be directly sent for decay $[67,68]$. We hypothesize that schistosomes may employ similar mechanisms, especially in such a dynamic structure as the tegument, which protects worms in the unfriendly blood environment of the host.

Antisense transcripts are frequently transcribed in eukaryotes and represent important regulators of gene expression; they control the state of chromatin or modulate the post-transcriptional fate of mRNAs $[69,70]$. We identified antisense transcripts of SmPOP, SmSP5, and SmCB1 only, and they were localized exclusively in the oviduct (Additional file 3: Figures S2 and S5). As known from previous research, these antisense transcripts most likely do not encode proteins but may control gene expression [69].

\section{Conclusions}

We validated and optimized a FISH method [23] for the detection of RNA transcripts in adult $S$. mansoni tissues. We documented the efficacy of the method by precise localization of the transcripts of selected proteins (SmCB1, SmPOP, SmTsp-2, and Sm29), whose distribution in schistosome adults was previously determined by other methods. In addition, we provided new insights into the localization of transcripts of these genes. Compared to RNAseq, FISH, due to its high sensitivity, is able to detect mRNA with low expression potential. The FISH methodology was then successfully applied to localize transcripts encoding serine proteases SmSP1 to SmSP5. Transcripts were found in S. mansoni females and males in various organs (parenchyma, tegument, reproductive organs) but with distinct patterns. Furthermore, we detected transcripts in previously unknown locations such as the syncytial part of the tegument or in tegumental tubercles. Based on the evidence of different transcript locations and our previous research [21,22], we hypothesize that SmSPs may play various physiological roles in host-parasite interaction, including regulation of the 
host vascular system, repair of stress-induced damage, and/or adaptation to changed conditions in the external environment. However, elucidation of the precise function of individual SmSPs is a matter of future studies.

\begin{abstract}
Abbreviations
DIG: Digoxigenin; FISH: Fluorescence in situ hybridization; HRP: Horseradish peroxidase; PBS: Phosphate-buffered saline; SSC: Standard saline citrate; SmSP1-5: S. mansoni serine protease 1-5; SmCB1: S. mansoni cathepsin B1; Sm29: Membrane-bound glycoprotein found on S. mansoni tegument, GenBank accession number AAC98911.1; SmPOP: S. mansoni prolyl oligopeptidase; SmTsp-2: S. mansoni tetraspanin 2.
\end{abstract}

\section{Supplementary Information}

The online version contains supplementary material available at https://doi. org/10.1186/s13071-021-04773-8.

Additional file 1: Table S1. Primers used to generate DIG-labelled RNA probes.

Additional file 2: Figure S1. Schematic representation of the adult S. mansoni surface and detailed micrograph of SmTsp-2 localization in the tegument and parenchyma of S. mansoni adult males.

Additional file 3: Figure S2. Localization of antisense mRNA of SmCB1, SmPOP, SmTsp-2 and Sm29 in adult S. mansoni females using FISH. Figure S3. Localization of antisense mRNA of SmCB1, SmPOP, SmTsp-2 and Sm29 in adult S. mansoni males using FISH. Figure S4. FISH with the probe for bacterial (neo) gene and a negative control (with no probe) in S. mansoni males and females. Figure S5. Localization of antisense mRNA of SmSP1 to SmSP5 in adult S. mansoni females using FISH. Figure S6. Localization of antisense mRNA of SmSP1 to SmSP5 in adult S. mansoni males using $\mathrm{FISH}$.

\section{Acknowledgements}

We would like to express our profound gratitude to Prof. John D. Brooker for critical proofreading of the manuscript and to Prof. Christoph G. Grevelding for providing plasmids for the Sm29 probe, for consultation, and for critical reading of the manuscript.

\section{Authors' contributions}

All authors contributed significantly to this study. JD and LU conceived and designed the experiments. JD, LU, and $\mathrm{MH}$ coordinated the study implementation. LU, MC, JD, and PO performed the experiments. LU, JD, and PO analyzed the data. $\mathrm{LU}, \mathrm{MH}$, and JD wrote and revised the paper. All authors read and approved the final manuscript.

\section{Funding}

JD was supported by the Operational Programme Research, Development and Education, the Call International Mobility of Researchers-MSCA- IF CZ.O 2.2.69/0.0/0.0/17_050/0008014 and by the Czech Science Foundation project 18-14167S and by the NutRisk Centre, CZ.02.1.01/0.0/0.0/16_019/0000845. $\mathrm{MH}$ was supported by the grants NV18-05-00345 from the Ministry of Health of the Czech Republic, 19-17269S from Czech Science Foundation, 8J19AT036 (OeAD CZ17/2019) from the Ministry of Education, Youth and Sports of the Czech Republic, and by the institutional project RVO 61388963. LU was supported by grant 1496214 from Charles University Grant Agency. PO was supported by the Charles University Research Fund (Progres Q39), by Charles University Research Centre program UNCE/MED/006 "University Center of Clinical and Experimental Liver Surgery" and by the National Sustainability Program I (NPU I) No. LO1503 provided by the Ministry of Education Youth and Sports of the Czech Republic. MC was supported by the Charles University Research Fund (Progres Q25).

\section{Availability of data and materials}

All data generated or analyzed during this study are included in this published article and its supplementary information files.

\section{Declarations}

Ethics approval and consent to participate

Research with experimental animals was performed in accordance with the animal welfare laws of the Czech Republic and under the European regulations for transport, housing and care of laboratory animals (Directive 2010/63/ EU on the protection of animals used for scientific purposes). This project, including the use of experimental animals for the present study, was approved by the Ministry of Education, Youth and Sports of the Czech Republic (Approval Number MSMT-7063/2017-2). All animals used in the study were maintained by a certified person (Certificate Number CZ 02627) in specifically accredited laboratories of the Institute of Immunology and Microbiology of the First Faculty of Medicine, Charles University and the General University Hospital in Prague (Accreditation Numbers 70030/2013-MZE-17214 and 8615/2019-MZE-17214), both issued by the Ministry of Agriculture of the Czech Republic.

\section{Consent for publication}

Not applicable.

\section{Competing interests}

The authors declare that they have no competing interests.

\section{Author details}

${ }^{1}$ Institute of Organic Chemistry and Biochemistry, The Czech Academy of Sciences, Flemingovo n. 2, 16610 Prague, Czech Republic. ${ }^{2}$ Department of Parasitology, Faculty of Science, Charles University, Viničná 7, 12844 Prague 2, Czech Republic. ${ }^{3}$ Biomedical Center, Faculty of Medicine in Pilsen, Charles University, Alej Svobody 1655/76, 32300 Pilsen, Czech Republic. ${ }^{4}$ Institute of Immunology and Microbiology, First Faculty of Medicine, Charles University and General University Hospital in Prague, Studničkova 2028/7, 12800 Prague, Czech Republic. ${ }^{5}$ Department of Zoology and Fisheries, Centre of Infectious Animal Diseases, Faculty of Agrobiology, Food and Natural Resources, Czech University of Life Sciences in Prague, Kamýcká 129, 16500 Prague 6, Czech Republic.

Received: 28 January 2021 Accepted: 3 May 2021

Published online: 22 May 2021

\section{References}

1. McManus DP, Dunne DW, Sacko M, Utzinger J, Vennervald BJ, Zhou XN. Schistosomiasis. Nat Rev Dis Primers. 2018:4:13.

2. Pearce EJ, MacDonald AS. The immunobiology of schistosomiasis. Nat Rev Immunol. 2002:2:499-511.

3. Lockyer AE, Olson PD, Ostergaard P, Rollinson D, Johnston DA, Attwood SW, et al. The phylogeny of the Schistosomatidae based on three genes with emphasis on the interrelationships of Schistosoma Weinland, 1858. Parasitology. 2003;126:203-24.

4. Gryseels B, Polman K, Clerinx J, Kestens L. Human schistosomiasis. Lancet. 2006:368:1106-18.

5. Burke ML, Jones MK, Gobert GN, Li YS, Ellis MK, McManus DP. Immunopathogenesis of human schistosomiasis. Parasite Immunol. 2009;31:163-76.

6. Berriman M, Haas BJ, LoVerde PT, Wilson RA, Dillon GP, Cerqueira GC, et al. The genome of the blood fluke Schistosoma mansoni. Nature. 2009;460:352-8.

7. Anderson CM, Zhang B, Miller M, Butko E, Wu X, Laver T, et al. Fully automated RNAscope in situ hybridization assays for formalin-fixed paraffinembedded cells and tissues. J Cell Biochem. 2016:117:2201-8.

8. Wong ML, Medrano JF. Real-time PCR for mRNA quantitation. Biotechniques. 2005;39:75-85.

9. Wendt G, Zhao L, Chen R, Liu C, O'Donoghue AJ, Caffrey CR, et al. A single-cell RNA-seq atlas of Schistosoma mansoni identifies a key regulator of blood feeding. Science. 2020;369:1644-9.

10. Buxbaum $A R$, Haimovich $G$, Singer $\mathrm{RH}$. In the right place at the right time: visualizing and understanding mRNA localization. Nat Rev Mol Cell Biol. 2015;16:95-109. 
11. LoVerde PT, Kuntz RE. Chromosome numbers of some schistosomes. J Parasitol. 1981;67:726.

12. Collins JJ 3rd, Wang B, Lambrus BG, Tharp ME, lyer H, Newmark PA. Adult somatic stem cells in the human parasite Schistosoma mansoni. Nature. 2013:494:476-9.

13. Sato H, Kusel JR, Thornhill J. Excretion of fluorescent substrates of mammalian multidrug resistance-associated protein (MRP) in the Schistosoma mansoni excretory system. Parasitology. 2004;128:43-52.

14. Collins JJ 3rd, King RS, Cogswell A, Williams DL, Newmark PA. An atlas for Schistosoma mansoni organs and life-cycle stages using cell type-specific markers and confocal microscopy. PLoS Negl Trop Dis. 2011;5:e1009.

15. Morris GP, Threadgold LT. Ultrastructure of the tegument of adult Schistosoma mansoni. J Parasitol. 1968;54:15-27.

16. Jones MK, Gobert GN, Zhang L, Sunderland P, McManus DP. The cytoskeleton and motor proteins of human schistosomes and their roles in surface maintenance and host-parasite interactions. BioEssays. 2004;26:752-65

17. Yang Y, Wen Y, Cai YN, Vallee I, Boireau P, Liu MY, et al. Serine proteases of parasitic helminths. Korean J Parasitol. 2015;53:1-11.

18. Dvořák J, Horn M. Serine proteases in schistosomes and other trematodes. Int J Parasitol. 2018;48:333-44.

19. McKerrow JH, Caffrey C, Kelly B, Loke P, Sajid M. Proteases in parasitic diseases. Annu Rev Pathol. 2006;1:497-536.

20. Dvořák J, Fajtová P, Ulrychová L, Leontovyč A, Rojo-Arreola L, Suzuki BM, et al. Excretion/secretion products from Schistosoma mansoni adults, eggs and schistosomula have unique peptidase specificity profiles. Biochimie. 2016:122:99-109.

21. Horn M, Fajtová P, Rojo Arreola L, Ulrychová L, Bartošová-Sojková P, Franta Z, et al. Trypsin- and Chymotrypsin-like serine proteases in Schistosoma mansoni-'the undiscovered country. PLoS Negl Trop Dis. 2014;8:e2766.

22. Leontovyč A, Ulrychová L, O’Donoghue AJ, Vondrášek J, Marešová L, Hubálek M, et al. SmSP2: A serine protease secreted by the blood fluke pathogen Schistosoma mansoni with anti-hemostatic properties. PLoS Negl Trop Dis. 2018;12:e0006446.

23. Ulrychová L, Horn M, Dvořák J. Sensitive fluorescence in situ hybridization on semithin sections of adult Schistosoma mansoni using DIG-labeled RNA probes. Methods Mol Biol. 2020;2151:43-53.

24. Jílková A, Horn M, Rezáčová P, Marešová L, Fajtová P, Brynda J, et al. Activation route of the Schistosoma mansoni cathepsin B1 drug target: structural map with a glycosaminoglycan switch. Structure. 2014;22:1786-98.

25. Jílková A, Horn M, Fanfrlík J, Küppers J, Pachl P, Řezáčová P, et al. Azanitrile inhibitors of the SmCB1 protease target are lethal to Schistosoma mansoni: structural and mechanistic insights into chemotype reactivity. ACS Infect Dis. 2021;7:189-201.

26. Horn M, Jilková A, Vondrášek J, Marešová L, Caffrey CR, Mareš M. Mapping the pro-peptide of the Schistosoma mansoni cathepsin B1 drug target: modulation of inhibition by heparin and design of mimetic inhibitors. ACS Chem Biol. 2011;6:609-17.

27. Jílková A, Řezáčová P, Lepšík M, Horn M, Váchová J, Fanfrlík J, et al. Structural basis for inhibition of cathepsin B drug target from the human blood fluke Schistosoma mansoni. J Biol Chem. 2011:286:35770-81.

28. Fajtová P, Štefanič S, Hradilek M, Dvořák J, Vondrášek J, Jílková A, et al. Prolyl Oligopeptidase from the blood fluke Schistosoma mansoni: from functional analysis to anti-schistosomal inhibitors. PLoS Negl Trop Dis. 2015:9:e0003827.

29. Cogswell AA, Collins JJ 3rd, Newmark PA, Williams DL. Whole mount in situ hybridization methodology for Schistosoma mansoni. Mol Biochem Parasitol. 2011;178:46-50.

30. Dillon GP, Illes JC, Isaacs HV, Wilson RA. Patterns of gene expression in schistosomes: localization by whole mount in situ hybridization. Parasitology. 2007;134:1589-97.

31. Pinheiro CS, Ribeiro AP, Cardoso FC, Martins VP, Figueiredo BC, Assis NR, et al. A multivalent chimeric vaccine composed of Schistosoma mansoni SmTSP-2 and Sm29 was able to induce protection against infection in mice. Parasite Immunol. 2014;36:303-12.

32. Oliveira SC, Figueiredo BC, Cardoso LS, Carvalho EM. A double edged sword: Schistosoma mansoni Sm29 regulates both Th1 and Th2 responses in inflammatory mucosal diseases. Mucosal Immunol. 2016;9:1366-71.

33. Cardoso FC, Macedo GC, Gava E, Kitten GT, Mati VL, de Melo AL, et al. Schistosoma mansoni tegument protein Sm29 is able to induce a
Th1-type of immune response and protection against parasite infection. PLoS Negl Trop Dis. 2008;2:e308.

34. Cardoso FC, Pacifico RN, Mortara RA, Oliveira SC. Human antibody responses of patients living in endemic areas for schistosomiasis to the tegumental protein Sm29 identified through genomic studies. Clin Exp Immunol. 2006;144:382-91.

35. Lu Z, Sessler F, Holroyd N, Hahnel S, QuackT, Berriman M, et al. A gene expression atlas of adult Schistosoma mansoni and their gonads. Sci Data. 2017:4:170118.

36. Lu Z, Sessler F, Holroyd N, Hahnel S, QuackT, Berriman M, et al. Schistosome sex matters: a deep view into gonad-specific and pairingdependent transcriptomes reveals a complex gender interplay. Sci Rep. 2016:6:31150.

37. Leontovyč A, Ulrychová L, Horn M, Dvořák J. Collection of excretory/ secretory products from individual developmental stages of the blood fluke Schistosoma mansoni. Methods Mol Biol. 2020;2151:55-63.

38. Štefanić S, Dvořák J, Horn M, Braschi S, Sojka D, Ruelas DS, et al. RNA interference in Schistosoma mansoni schistosomula: selectivity, sensitivity and operation for larger-scale screening. PLoS Negl Trop Dis. 2010;4:e850.

39. Schindelin J, Arganda-Carreras I, Frise E, Kaynig V, Longair M, Pietzsch T, et al. Fiji: an open-source platform for biological-image analysis. Nat Methods. 2012;9:676-82.

40. Sajid M, McKerrow JH, Hansell E, Mathieu MA, Lucas KD, Hsieh I, et al. Functional expression and characterization of Schistosoma mansoni cathepsin B and its trans-activation by an endogenous asparaginyl endopeptidase. Mol Biochem Parasitol. 2003;131:65-75.

41. Schulte L, Lovas E, Green K, Mulvenna J, Gobert GN, Morgan G, et al. Tetraspanin-2 localisation in high pressure frozen and freeze-substituted Schistosoma mansoni adult males reveals its distribution in membranes of tegumentary vesicles. Int J Parasitol. 2013;43:785-93.

42. Bogitsh BJ, Dresden MH. Fluorescent histochemistry of acid proteases in adult Schistosoma mansoni and Schistosoma japonicum. J Parasitol. 1983;69:106-10.

43. Tran MH, Pearson MS, Bethony JM, Smyth DJ, Jones MK, Duke M, et al. Tetraspanins on the surface of Schistosoma mansoni are protective antigens against schistosomiasis. Nat Med. 2006;12:835-40.

44. Tran MH, Freitas TC, Cooper L, Gaze S, Gatton ML, Jones MK, et al. Suppression of mRNAs encoding tegument tetraspanins from Schistosoma mansoni results in impaired tegument turnover. PLoS Pathog. 2010:6:e1000840

45. QuackT, Knobloch J, Beckmann S, Vicogne J, Dissous C, Grevelding CG. The formin-homology protein SmDia interacts with the Src kinase SmTK and the GTPase SmRho1 in the gonads of Schistosoma mansoni. PLoS ONE. 2009:4:e6998.

46. Meemon K, Grams R, Vichasri-Grams S, Hofmann A, Korge G, Viyanant V, et al. Molecular cloning and analysis of stage and tissue-specific expression of cathepsin B encoding genes from Fasciola gigantica. Mol Biochem Parasitol. 2004;136:1-10.

47. Jedličková L, Dvořáková H, Dvořák J, Kašný M, Ulrychová L, Vorel J, et al. Cysteine peptidases of Eudiplozoon nipponicum: a broad repertoire of structurally assorted cathepsins $L$ in contrast to the scarcity of cathepsins $B$ in an invasive species of haematophagous monogenean of common carp. Parasit Vectors. 2018:11:142.

48. Irwin SW, Threadgold LT. Electron microscope studies of Fasciola hepatica X Egg formation. Exp Parasitol. 1972;31:321-31.

49. Medina M, Leon P, Vallejo CG. Drosophila cathepsin B-like proteinase: a suggested role in yolk degradation. Arch Biochem Biophys. 1988:263:355-63.

50. Zhao XF, Wang JX, Xu XL, Schmid R, Wieczorek H. Molecular cloning and characterization of the cathepsin B-like proteinase from the cotton boll worm Helicoverpa armigera. Insect Mol Biol. 2002;11:567-75.

51. Andreu Z, Yanez-Mo M. Tetraspanins in extracellular vesicle formation and function. Front Immunol. 2014;5:442.

52. Erasmus DA. A comparative study of the reproductive system of mature, immature and "unisexual" female Schistosoma mansoni. Parasitology. 1973:67:165-83.

53. Wang J, Collins JJ 3rd. Identification of new markers for the Schistosoma mansoni vitelline lineage. Int J Parasitol. 2016;46:405-10.

54. Cocude C, Pierrot C, Cetre C, Fontaine J, Godin C, Capron A, et al. Identification of a developmentally regulated Schistosoma mansoni serine 
protease homologous to mouse plasma kallikrein and human factor I. Parasitology. 1999;118:389-96.

55. Nawaratna SS, McManus DP, Moertel L, Gobert GN, Jones MK. Gene Atlasing of digestive and reproductive tissues in Schistosoma mansoni. PLoS Negl Trop Dis. 2011;5:e1043

56. Wang J, Yu Y, Shen H, Qing T, Zheng Y, Li Q, et al. Dynamic transcriptomes identify biogenic amines and insect-like hormonal regulation for mediating reproduction in Schistosoma japonicum. Nat Commun. 2017;8:14693.

57. Barckmann B, Simonelig M. Control of maternal mRNA stability in germ cells and early embryos. Biochim Biophys Acta. 2013;1829:714-24.

58. Shakes DC. For male Caenorhabditis elegans, sperm activation is a "just-intime" event. PLoS Genet. 2011;7:e1002392.

59. Zhao Y, Sun W, Zhang P, Chi H, Zhang MJ, Song CQ, et al. Nematode sperm maturation triggered by protease involves sperm-secreted serine protease inhibitor (Serpin). Proc Natl Acad Sci U S A. 2012;109:1542-7.

60. Kelleher ES, Pennington JE. Protease gene duplication and proteolytic activity in Drosophila female reproductive tracts. Mol Biol Evol. 2009:26:2125-34.

61. Kruger FJ, Schutte CH, Visser PS, Evans AC. Phenotypic differences in Schistosoma mattheei ova from populations sympatric and allopatric to $S$. haematobium. Onderstepoort J Vet Res. 1986;53:103-7.

62. Braschi S, Borges WC, Wilson RA. Proteomic analysis of the schistosome tegument and its surface membranes. Mem Inst Oswaldo Cruz. 2006:101(Suppl 1):205-12.
63. Sotillo J, Pearson M, Potriquet J, Becker L, Pickering D, Mulvenna J, et al. Extracellular vesicles secreted by Schistosoma mansoni contain protein vaccine candidates. Int J Parasitol. 2016:46:1-5.

64. Blower MD. Molecular insights into intracellular RNA localization. Int Rev Cell Mol Biol. 2013;302:1-39.

65. Martin KC, Ephrussi A. mRNA localization: gene expression in the spatial dimension. Cell. 2009:136:719-30.

66. Gibbings DJ, Ciaudo C, Erhardt M, Voinnet O. Multivesicular bodies associate with components of miRNA effector complexes and modulate miRNA activity. Nat Cell Biol. 2009;11:1143-9.

67. Rajgor D, Shanahan CM. RNA granules and cytoskeletal links. Biochem Soc Trans. 2014:42:1206-10.

68. Anderson P, Kedersha N. RNA granules: post-transcriptional and epigenetic modulators of gene expression. Nat Rev Mol Cell Biol. 2009;10:430-6.

69. Pelechano V, Steinmetz LM. Gene regulation by antisense transcription. Nat Rev Genet. 2013;14:880-93.

70. Nishizawa M, Okumura T, Ikeya Y, Kimura T. Regulation of inducible gene expression by natural antisense transcripts. Front Biosci. 2012;17:938-58.

\section{Publisher's Note}

Springer Nature remains neutral with regard to jurisdictional claims in published maps and institutional affiliations.
Ready to submit your research? Choose BMC and benefit from:

- fast, convenient online submission

- thorough peer review by experienced researchers in your field

- rapid publication on acceptance

- support for research data, including large and complex data types

- gold Open Access which fosters wider collaboration and increased citations

- maximum visibility for your research: over $100 \mathrm{M}$ website views per year

At BMC, research is always in progress.

Learn more biomedcentral.com/submissions 